Ernesto Ottone y Jorge Navarrete: Debatiendo sin ira

(Santiago: Catalonia, 2012).

\title{
UNA CUESTIÓN DE TONO
}

\author{
Arturo Fontaine
}

M

enté en un sillón de mi departamento y de repente había terminado Debatiendo sin ira (Catalonia, 2012). Se me acabó tan rápido... Después caí en la cuenta del tremendo mérito que era eso. Una conversación política - una más de las miles y miles que me han tocado en mi vida - me había absorbido por completo, al punto de que no sabía cuánto rato había pasado.

¿Por qué captura así este libro? Porque asistimos a una conversación honesta. Las preguntas de Jorge Navarrete, por supuesto, son inteligentes y a ratos muy incisivas. Pero sobre todo, son preguntas verdaderas. Jorge Navarrete no busca lucirse ni exagerar ni plantear cuestiones alambicadas. No hay narcisismo alguno en quien interroga sino un volcarse por completo al asunto mismo. Las preguntas son todas sencillas, pero reales. Son las preguntas que todos queremos hacerle a Ottone.

Y Ottone, por su parte, contesta en el mismo plano, sin estridencias, sin golpes de efecto, a veces, con ironía, pero siempre con una sabiduría humilde. Una humildad auténtica que no proviene de un deber ser, sino de haber vivido como comunista comprometido el esplendor y el desplome de la utopía comunista, de haber conocido el triunfo y

Arturo Fontaine. Escritor. Director del CEP y profesor del Departamento de Filosofía de la Universidad de Chile. afontaine@cepchile.cl. 
el fracaso en la política democrática, y la opresión bajo la dictadura. Una humildad que proviene de haber experimentado el dolor en carne propia. En fin, una humildad que nace de haber estado en el epicentro del Poder, de conocer sus grandezas y miserias, vericuetos y vicisitudes, y de haber experimentado sus límites. Porque si hay algo que trasmite Ottone sin decirlo es eso: las restricciones que inevitablemente cercan a quien está en el poder. Desde fuera, conquistar el poder parece que lo permitirá todo. Desde adentro, la cosa se ve al revés. Ottone ha conocido las impotencias del poder y habla desde ahí. Su mirada y su tono es descarnado y desmantela el anhelo utópico. Porque las utopías políticas siempre sobredimensionan el poder del poder.

En tal sentido, ironiza, por ejemplo, a quienes critican la timidez de los gobiernos de la Concertación y separan a los "gradualistas impenitentes" de los "audaces frustrados". (Generalmente son los "audaces frustrados" quienes plantean así las cosas.)

Ottone fue un dirigente comunista importante, fue presidente de la Federación Mundial de la Juventud Democrática, organización internacional que agrupaba a las juventudes de los partidos comunistas. $\mathrm{Y}$ en esa calidad recorrió diversos lugares del mundo. "Mi rompimiento", cuenta en este libro, pasa por la invasión de la Unión Soviética a Afganistán, el golpe de Estado prosoviético en Polonia, la guerra entre China y Vietnam — dos países comunistas hermanos-, la Camboya de Pol Pot "donde estuve inmediatamente después de su caída y me tocó presenciar horrorizado los efectos de un genocidio en nombre de la revolución", y en África "el paso exultante del colonialismo opresor a la libertad y de la libertad al hambre y la corrupción" (p. 101). No estamos hablando de problemas teóricos. Ottone da aquí testimonios personales.

Pareciera que Ottone se decepciona primero de la vía revolucionaria, es decir, en términos marxistas pasa a ser un reformista. "Sabemos que la experiencia del socialismo real, que pude vivirla personalmente, terminó generando un igualitarismo lleno de privilegios para los notables del régimen y clasurando buena parte de las libertades" (p. 81). Ante la violencia y sus frutos valoriza el gradualismo y la vía pacífica. Los "derechos burgueses", la "democracia formal" cobran a sus ojos un sentido muy real y concreto. Protegen la vida, protegen el pluralismo, enmarcan la libertad, permiten la democracia. Si la ruptura revolucionaria no da pie a la construcción de formas democráticas, viene a continuación el horror de las violaciones a los derechos humanos. En el 
libro, Ottone vuelve sobre esto varias veces y, al mismo tiempo, insiste en la fragilidad de las instituciones democráticas.

Luego viene un paso sin duda más difícil. Navarrete hábilmente lo lleva explicarlo. Es lo que, siguiendo a Ottone, podríamos llamar "el caso del unicornio, del animal que no existe". Dice Ottone: "Si nos atenemos a las formas históricas hoy existentes, tú puedes tener democracia y capitalismo, y también dictadura y capitalismo. El unicornio, el animal que no existe, es el que combina democracia y socialismo real o economía centralmente planificada. La historia es implacable al respecto" (p. 83). Por lo tanto, si queremos democracia vamos a tener que aceptar el capitalismo.

Ottone no se detiene a demostrar por qué los regímenes comunistas no logran construir democracias. Pero el lector puede inferir del caso del unicornio, que al destruir el capitalismo destruyen la posibilidad de que haya democracia. Con todo, es claro que hay instituciones específicamente políticas cuya ausencia deriva en dictadura y que se dan por sabidas. A mí, como lector, me hubiera gustado un poco más de desarrollo en este punto. Por otra parte, la justificación del capitalismo aparece sólo en función de la democracia. Ottone no se ocupa de explicar por qué el capitalismo crea riqueza, permite combatir la pobreza y, como ha ocurrido en Chile, ensancha las capas medias. También se da por sabido. Tampoco se muestra sociológicamente lo que una sociedad capitalista significa en términos de procesos de individuación y pluralismo en el campo ético-cultural, por ejemplo. Nada hay sobre la cuestión del consumismo y la alienación, temas clásicos que siguen dando vueltas... O sobre el ethos capitalista y la sociedad chilena. ¿Ha echado raíces o no?

¿Nos gusta esta ciudad con malls? Pienso que nadie quiere un mall al frente de su casa, o que el mall destruya un paisaje natural o urbano muy valioso. Pero estoy convencido de que de hecho la inmensa mayoría quiere poder ir al mall. Un intelectual no debe decir esto: creo que buena parte de la población siente que su presencia es un paso civilizatorio. Las ciudades tradicionales se constituyen en torno a la plaza, la iglesia, el mercado. El mall es un mercado y, a la vez, una plaza protegida. Pero muchos dirigentes de la Concertación y muchos intelectuales no se sienten cómodos con una sociedad capitalista como la que los gobiernos de la Concertación han procurado. 
Algo parecido me ocurre con la defensa que hace de la obra de la Concertación en el campo socioeconómico. Se menciona, por cierto, el enorme cambio "como diría el viejo Marx, en las condiciones materiales de existencia", "lo que parecía inalcanzable tendió a alcanzarse", se habla del "salto en el nivel de vida y las expectativas" (p. 11). Pero yo hubiera esperado más cifras reveladoras, algunos datos impactantes para mostrar de qué estamos hablando en materias de crecimiento y pobreza, por ejemplo. Mal que mal la pobreza pasó del 45,1\% en 1987 al 13,7\% el 2006. La pobreza extrema o indigencia era de $17,4 \%$ el 87 y 11 egó al 3,2\% el 2006. Son logros impresionantes. La inflación que era $26 \%$ en 1990, en 1995 ya era de un dígito y llegó a ser del 1,5\% el 2009. Se podría decir que la Concertación derrotó la inflación. En materia de desigualdad, en cambio, no ha habido cambios; ni mejora ni empeoramiento. Aquí, claro, hay un gran desafío pendiente.

En particular, yo quería ver una explicación de qué políticas hicieron posible ese crecimiento y esa reducción de la pobreza. Esta "nueva sociedad" que pasa de un ingreso de 6.000 dólares per cápita a cerca de 12.000 dólares per cápita no cayó del Cielo; es el resultado de ciertas políticas que los gobiernos de la Concertación propugnaron. A veces, venciendo grandes dificultades y contra la corriente. Uno quisiera saber cuáles, en la visión de Ottone, fueron las esenciales. Y cuáles sería necesario mantener en un futuro gobierno.

Una buena conversación se hace corta, uno quiere seguir y cuando ha terminado uno tiene la sensación de que la conversación recién comienza. Es lo que pasa con este libro. Uno quiere que continúe, que se exploren además otros temas, en fin, que los amigos no se separen todavía y sigan hablando. El lector espera en este caso una próxima conversación, unas segundas partes. Estas impresiones mías quisieran tentarlos.

Por cierto, así como la democracia admite diversos sistemas de gobierno y una enorme variedad de sistemas electorales (piensen un momento en lo peculiar que es el sistema electoral norteamericano, por ejemplo), de la misma manera el capitalismo admite toda una gama de modalidades. No es lo mismo el capitalismo sueco que el de Singapur.

Ottone se ve como un socialdemócrata y cree que la socialdemocracia debe "repensar profundamente [...] cómo producir en el mundo de hoy la síntesis de igualdad y libertad de la que fue portadora en el pasado" (p. 47). 


\section{Los tres problemas de hoy}

Dado ese marco, diría que Ottone ve tres problemas centrales en el Chile de hoy. A su juicio, se ha cerrado un ciclo político y se inicia uno nuevo que requiere algo así como un nuevo pacto político.

\section{El problema número uno es la desigualdad}

Esta "deformidad" es la expresión que usa. "Si tú entras al décimo decil y te vas a los últimos centiles, la acumulación de la riqueza es gigantesca, desmesurada" (p. 73). "Hoy día el eje de la política debe desplazarse necesariamente al tema de la creación de una sociedad menos desigual" (p. 49). La solución pasa por una importante reforma tributaria. Sin embargo, no se detiene a esbozar las características de dicha reforma. Critica, por insuficiente, la reforma tributaria del gobierno actual. Menciona, a modo de ejemplo, la educación como destino de los fondos. A uno se le despierta la curiosidad: quisiera saber con qué prioridades, con qué criterios básicos debieran asignarse esos fondos recaudados. Y qué esperar de ellos en términos de reducción de las desigualdades y a qué plazo.

\section{Problema número dos, la crisis de los partidos}

Para Ottone aquí parece estar el meollo del problema actual: "Se requiere que los partidos de centro-izquierda se renueven hasta el tuétano" (p. 38). Los partidos políticos no han estado a la altura. Propone primarias a todos los niveles, nueva ley de partidos que abra los partidos y facilite la rendición de cuentas, un cambio del sistema electoral. La democracia de hoy no es una democracia de masas sino "una democracia de opinión pública". Sostiene que "el progresismo de mañana va a ser un progresismo de los individuos, complejo y opinante, las personas no entregarán una adhesión incondicional, a una idea, a un partido y menos a una ideología". La renovación planteada va incluso más allá de lo político y se debe abrir un "debate sobre la ética reformadora. Lo importante es repensar esa cosa común, ese espacio compartido de la centro-izquierda y no provocar un mosaico fragmentado de sensibilidades que viven identidades sectarias y estériles o grupos asociados solo en torno a cuotas de poder" (p. 41). 
Navarrete le plantea una crítica que algunos hacen al gobierno de Michelle Bachelet: su "gobierno ciudadano" y su estilo favorecen su propia popularidad en desmedro de los partidos, "dejando a la clase política tradicional como la principal responsable de los males que menoscaban el debate público" (p. 17). Ottone estima injusta esa crítica. El deterioro de los partidos venía de antes. Celebra la forma en que manejó la economía en tiempos de bonanza, gracias a lo cual pudo realizar una eficaz política contra-cíclica y de protección social cuando vino la crisis económica mundial. "Eso fue muy bien comprendido por la gente", afirma. Es decir, se mantuvo la política de balance estructural iniciada en el gobierno de Ricardo Lagos. A ella se debe, en importante medida, la solidez y prestigio de la economía chilena. Y más adelante, en lo que podría ser su idea central a este respecto: "Los gobiernos de la Concertación son lo mejor de la Concertación” (p. 33).

\section{Problema número tres, la mala memoria}

Hay una polémica implícita en el libro. Ottone está criticando a quienes vaticinan que el sistema socioeconómico imperante colapsó, se derrumbó y añoran un nuevo tipo de organización política y socioeconómica por definir. Las inmensas marchas estudiantiles del 2011 detonaron este descontento y lograron indudable resonancia en la sociedad. ¿Hay un clima revolucionario o pre-revolucionario, quizás?

Ottone no está de acuerdo. Sugiere que muchos estudiantes, nacidos en democracia, ignoran lo frágil que es la democracia y lo difícil que es construirla. Es crítico de algunos aspectos de lo que hizo la Concertación, por ejemplo, en educación superior.

Mi impresión es que ni se intentó siquiera tomar medidas para impedir que universidades sin fines de lucro, de hecho, fueran empresas con fines de lucro. Esta conducta abusiva contraria al espíritu de la ley de ciertos mercaderes de la educación ha sido uno de los motores del movimiento estudiantil.

La rapidísima expansión de la matrícula universitaria se publicitó como un gran logro y en ello el CAE, el sistema de préstamos con aval del Estado para estudiantes de las universidades privadas - con y sin fines de lucro- ha jugado un papel. Surgió un mercado de universidades "sin fines de lucro" que comenzaron a transarse en cientos de millones de dólares como si fueran cadenas de supermercados. Un rector en 
entrevista a Qué Pasa llegó a decir que el negocio se parecía mucho al del retail... Gran parte de las familias, incluso familias muy pobres, con inmenso sacrificio, han financiado parcial o totalmente los estudios universitarios de sus hijos en el convencimiento de que eso les aseguraba un futuro muy superior al de sus padres y al que les esperaba si no lo hacían. Era lo que las autoridades y los expertos prometían. Se creyó que el empresario capitalista financiado por el Estado iba a cumplir el sueño de "la universidad para todos". Bueno, el sueño empieza a cumplirse y los resultados empiezan a percibirse. Dostoievsky habló en su tiempo de que se había creado velozmente en Rusia "un proletariado de bachilleres". Esa fue, a su juicio, la incubadora del nihilismo revolucionario. No pienso que la situación en Chile sea esa, pero conviene tener presente a Dostoievsky.

El asunto tiene que ver, por cierto, con la movilidad social y afecta incluso la legitimidad del sistema. Se argumentó que como las desigualdades de ingresos estaban muy vinculadas al título universitario, aumentando los títulos universitarios iba a disminuir entonces la desigualdad. El supuesto era que la calidad de la formación universitaria y su costo fueran adecuados. Bueno, estudios recientes de rentabilidad hechos por Sergio Urzúa en el CEP indican que algo del 40\% de los titulados cuando ya están en el mundo laboral no recuperan la inversión que les significaron esos estudios universitarios, es decir, "salen para atrás". La promesa no se cumple para ellos. Buena parte de nuestras universidades son caras y malas. El sistema universitario está mal diseñado y su corrección será difícil políticamente y onerosa para el Fisco. Se requiere cirugía mayor. El movimiento estudiantil puso el dedo en la llaga.

Nada se dice en este libro sobre el financiamiento compartido, una reforma clave introducida por un gobierno de la Concertación y que cuenta con gran respaldo en la sociedad, según lo muestra el comportamiento de los padres y su opinión en las encuestas. El financiamiento compartido, por una parte, permitió aumentar los recursos, amplió la libertad de los padres al permitirles aportar a la educación de sus hijos, consiguió colegios más afines a su visión de mundo y contribuyó mucho a la diversidad del sistema educacional. Pero por otra, acentuó la segregación y les ha dado una ventaja económica a los colegios particular-subvencionados vis-à-vis las escuelas y los liceos públicos. ¿Cómo evalúa Ottone hoy esta política? Se trata de una innovación de la Concertación que está en el corazón de la protesta estudiantil. 


\section{Una cuestión de tono}

Con todo $-\mathrm{y}$ esto vale también para las demás omisiones que he señalado - uno siente adónde va Ottone: no está tan preocupado en esta conversación de los contenidos, de examinar o proponer políticas específicas. Más bien de lo que trata en este libro sencillo y lúcido es de algo más fundamental, aunque a primera vista no lo parezca. Es una cuestión de tono. A lo que de verdad Ottone atribuye importancia es al tono en que se plantean las propuestas y discusiones.

Creo que quien mejor ha combinado en nuestra época el conocimiento y la mente del intelectual con la destreza para discernir lo adecuado en el aquí y ahora en el día a día de la política es Ernesto Ottone. A esa virtud, a esa inteligencia en la acción, Aristóteles llamó "frónesis". Lo que desde su cultura, su inteligencia, su experiencia, su sabiduría quiere corroer es un cierto modo mesiánico de entender la política. Y eso calza bien con su convicción de que la democracia es antes que nada un conjunto de procedimientos.

Diría que el mensaje de Ottone es sutil y es profundo: lo esencial en política es el tono y los procedimientos. Nos lo dice un viejo zorro de la política.

Y a los profetas que vaticinan el derrumbe de la obra de la Concertación y hablan de la revolución por venir, Ottone les recuerda con ironía la frase de Marx en el 18 de Brumario de Luis Bonaparte, la revolución del segundo Napoléon, el pequeño, de Napoleón III. Dice Marx: "la historia sucede primero como tragedia y después como farsa". Concluye Ottone: ahora "hay que cuidarse de la farsa" (p. 101). 